\title{
Mindfulness Meditation as a Complementary Health Therapy: A Useful Import into Africa?
}

\author{
Esther Ejiroghene Ajari ${ }^{1,2,3 *}$
}

${ }^{1}$ College of Medicine, University of Ibadan, Ibadan, Oyo State, NIGERIA
${ }^{2}$ The TriHealthon, Ibadan, Oyo State, NIGERIA
${ }^{3}$ Center for Contemplative Science, University of Virginia, Charlottesville, Virginia, USA
${ }^{*}$ Corresponding Author: estherejiroghene@gmail.com

Citation: Ajari, E. E. (2020). Mindfulness Meditation as a Complementary Health Therapy: A Useful Import into Africa?. European Journal of Environment and Public Health, 4(2), em0048. https://doi.org/10.29333/ejeph/8328

\section{ARTICLE INFO}

Received: 8 Apr. 2020

Accepted: 14 May 2020

\begin{abstract}
Mindfulness meditation, a very common contemplative practice used to attain a conscious state of awareness, acceptance, openness and non-reactivity, was first modified in 1979 into a complementary health therapeutic practice. This practice has, since, gained the attention of scholars globally, with the greatest surge in interest seen in the last two decades. However, in Africa, research output on the psychological construct is very limited and certified trainers of the practice are almost non-existent despite the fact that the practice has been shown to relieve stress, a factor whose level is high in the continent, and has been associated with many common disease, illnesses and other negative outcomes. There is, therefore, an overwhelming need to draw public attention towards the practice and what it can offer African healthcare systems. However, this paper takes a neutral tone while creating this needed awareness, acting just as a guide towards unravelling the complexities of the practice and not as an advocacy piece promoting its implementation in healthcare systems across Africa. It achieves this aim by discussing the major reported positive and negative physiological effects of the practice; its application in the therapy of some common physical and mental disease/illness conditions; its benefits to healthcare workers and students, and informal caregivers; its limitations; the popular criticisms levelled against it; and factors in support and against its incorporation into African healthcare systems. The discourse is concluded with recommendation of strategies for refining the practice to suit the African healthcare scene.
\end{abstract}

Keywords: Mindfulness, Meditation, Health, Therapy, Africa, Complementary

\section{INTRODUCTION}

There is no universally acceptable definition of the term, "mindfulness". It has a plethora of meanings: an indication of the term's popularity (Van Dam et al., 2017). But the most popular definition states that mindfulness is a doublecomponent psychological process that includes paying attention to present moment experience and possessing an attitude of openness, non-reactivity and acceptance (KabatZinn, cited in Norris et al., 2018). The process of cultivating mindfulness usually involves the following elements: a calm environment with as few distractions as possible; a specific and convenient posture or activity (sitting, lying down, walking, running, dancing etc.); a focus of attention (a specially chosen word, phrase, clause, statement, object, or bodily sensation such as breath, heartbeat, muscle tension, fatigue, tactile pressure etc.); and an open attitude (letting distractions come and go quietly without judging them).
Meditation, on the other hand, is a term that describes a large number of contemplative practices used in attaining a state of consciousness that differs from the normal waking state. These practices include mindfulness meditation, compassion-based meditation, body scan meditation, vipassana or insight meditation, shamatha or calm binding meditation, dzogchen meditation, zen meditation, pranayama meditation, metta or loving kindness meditation etc. Mindfulness meditation is, arguably, the most popular type of meditation in the West. Moreover, it is not uncommon for people to equate mindfulness meditation with mindfulness. However, mindfulness meditation is just a very common, not the only, mindfulness practice. Other mindfulness practices include movement-based contemplative practices (e.g. Yoga, Tai Chi, Qigong, contemplative dancing etc.), contemplative writing, contemplative prayer, spending quality time in the natural world etc. Simply put, if mindfulness is like strength or flexibility, mindfulness meditation and other mindfulness practices are like running or going to the gym. 
Complementary health therapy is known by many different terms such as complementary medicine, alternative therapy, alternative medicine, add-on-therapy, adjunct therapy, traditional medicine etc. According to the United States National Centre for Complementary and Alternative Medicine (US NCCAM), this therapy refers to various health care products, practices, and systems that are not currently regarded as part of conventional medicine. In Africa, herbal medicine is the most common example of complementary therapy and even this is no longer dominant or well recognized in the continent due to westernization (Abdullahi, 2011). Other examples of complementary therapy include clinically modified contemplative practices, chiropractic and osteopathic medicine, body-movement medicine, acupuncture, homeopathy, oriental practices, reflexology etc. The US NCCAM classifies these examples into six distinct types: alternative medical systems, biologically-based therapies, manipulative and body-based practices, mind-body therapies, energy medicine, and self-prayer. Mind-body therapies are the most commonly used complementary therapy in the United States (Wahbeh et al., 2008) with mindfulness-based stress reduction (MBSR) therapy, introduced in 1979, being its earliest form and the base from which mindfulness-based cognitive therapy (MBCT), another common form of mind-body therapy, was created. The goldstandard model of MBSR therapy is an 8-week formal course involving 20-26 hours of mindfulness meditation split across a 1.5-2.5 hour-long group class/week, a straight 6-hour class during any of the weeks, and regular home practice of about 45 minutes/day, 6 days/week (Van Dam et al., 2017).

From 2000 to 2015, there was, approximately, a $400 \%$ increase in original articles on mindfulness and/or meditation in scientific journals and a $540 \%$ increase in media pieces on the subject matter in newspapers globally (Van Dam et al., 2017). This represents a rapid growth of interest in the study of mindfulness and meditation. In addition, Van Dam et al. posits that the promising reports from these investigations made mindfulness meditation go from being an inessential aspect of scholarly curiosity to being an adjunct therapy for chronic diseases, an occasional substitute for psychotherapy, a tool for improving corporate well-being, and a widely thought practice. However, the practice and the empirical evidence supporting it have not gone without criticisms. These criticisms may be the reason behind the lack of global recommendation of the practice as a useful therapy. Its retained status as just an example of complementary health therapy practised in some parts of the world, and its historical origin from religions (such as Buddhism, Hinduism, Taoism, Jainism, Stoicism etc.) which are unpopular in Africa, may be reasons for its lack of popularity in the African continent.

The aim of this paper is to guide African policymakers and the general African public to deduce for themselves the potentials or lack thereof of mindfulness meditation as a tool for healthcare improvement in Africa. It does this by; (1) Discussing the major, positive and general physiological effects of the practice that has been reported and its application in the prevention and management of some common diseases such as HIV/AIDS, cancer, dementia, cardiovascular diseases, asthma, psoriasis, mental disorders (e.g. depression, anxiety, substance abuse, sleep disorders, post-traumatic stress disorder, suicidal behaviour disorder, and menstrually-related mood disorders). (2) Outlining some reported benefits of the practice to healthcare workers and students as well as informal caregivers (3) Highlighting the little-known and seldom-discussed negative effects of the practice (4) Summarizing the popular criticisms levelled against the practice (5) Highlighting the limitations of the practice (6) Discussing factors that favour and factors that does not favour the incorporation of the practice into African healthcare systems (7) Recommending ways for improving the practice to suit the African healthcare scene.

Worthy of note is the fact that in this article, the scope of the term "mindfulness meditation" includes both informal and formal clinical modification of the practice, especially MBSR and MBCT.

\section{DISCUSSION}

Stress is at the epicentre of many negative behaviours that contribute to unhealthy living. These behaivours include smoking, food and alcohol overconsumption, imbalanced diets, and inadequate or lack of physical activity (Victorson et al., 2015). Psychological stress alters insulin needs and thus, increases the risk for diabetes mellitus, particularly in overweight individuals (Salleh, 2008). Other findings highlighted by Salleh are; (1) Stress can lead to peptic ulcers, stress ulcers or ulcerative colitis by increasing the stomach hydrochloric acid concentration (2) Chronic stress has significant effect on the immune system such as increasing catecholamine and decreasing concentration of T-cells which leads to immune suppression. This suppression, in turn, raises the risk for viral infections and other diseases (3) Chronic stress can lead to atherosclerosis, especially if compounded with sedentary lifestyle and diet containing high fat concentration. Several studies have also revealed that psychological stress may account for some of the variability in treatment outcomes of several diseases or illnesses. These examples are, by no means, an exhaustion of the resultant effects of acute and chronic stress. It is a complex and sometimes overlapping sequence. However, reactive and automatic stress reactions can be short-circuited by mindfulness meditation, a practice which teaches receptive awareness and appreciation of one's present experience and/or situation (Victorson et al., 2015).

In Africa, stress levels are high (Hjelm et al., 2017) but this is not surprising, considering the low-income level, food insecurity, high violence rate, insensitive work and school environment and other stressors present in the continent. Therefore, several teachers of mindfulness meditation have recommended the import of the practice into Africa. Some scientific evidences of an unexhausted list of benefits, which can be achieved from the implementation of this recommendation, are detailed below.

\section{General Positive Physiological Effects of Mindfulness Meditation}

Mindfulness meditation has been reported to improve attention (Creswell, 2016; Hölzel et al., 2011; Norris et al., 2018; Sedlmeier et al., 2012), executive functioning (Gallant, 
2016), working memory and retention (Brown et al., 2016), cognition (Zeidan et al., 2010), negative emotion and mood (Goyal et al., 2014; Wu et al., 2019), personality traits (Crescentini et al., 2018), creativity (Ding et al., 2014), stamina (Robins et al., 2014), and weight loss (Carrière et al., 2018; KayLoni and Emery, 2015). These findings were generated through various research with study design types ranging from quasi or randomized controlled experiments to systematic analysis.

Improvement of attentional processes such as alerting, orienting, and executive attention might be the most apparent effect of mindfulness meditation. This is due to the fact that the basics of the practice, itself, involves: noticing when one's attentional focus is distorted, letting go of the distraction and then, returning focus to the initial stimulus (sustained attention) or separating attentional resources to two/more stimuli at the same time or shifting attention to a different aspect of one stimulus in a way that it changes one's initial perception of the stimulus (divided attention). Filgueiras et al. (2015) propounds that attentional control is at the epicentre of executive functioning and thus, a mindfulness-associated improvement in attentional control is likely to improve executive functions. Also, attentional control level is a strong predictor of working memory capacity (Baltar \& Filgueiras, 2018) and working memory capacity is a strong predictor of cognition and cognitive flexibility (Meier and Kane, 2015).

Furthermore, Hölzel et al. (2007) reported an association between mindfulness meditation and increased activation in the rostral anterior cingulate cortex of the brain, a pivotal area in the nervous system involved in the processing of emotional information, suggesting that mindfulness may cause emotional regulation. Other studies have, since, solidified the claim. There are also results in several investigations suggesting that mindfulness improves perceived ability to shift one's mood (Baltar and Filgueiras, 2018). Also, self-report inventories such as the Five-Factor Model of Personality Traits and the Temperament and Character Inventory were used to establish the link between mindfulness and improved personality (Crescentini and Capurso, 2015). Furthermore, there is a proportional link between mood and creativity (Zenasni and Lubart, 2002) and between personality and creativity (Prabhu et al., 2008).

Also, although a direct link between stamina improvement and weight loss has not been properly established, increased physical activity is well-known to improve both stamina and weight loss. Thus, an argument can be made that if mindfulness improves one of the variables, then, a concurrent improvement in the other variable can result.

\section{Positive Effects of Mindfulness Meditation on Some Physical Diseases}

Creswell et al. (2009) provided an initial indication that mindfulness meditation can increase the levels of CD4+ T lymphocyte in HIV-1 infected adults. Webb et al. (2017) supported this finding by reporting that patients practising mindfulness meditation were significantly more likely to change their HIV viral loads from high to low (44\% of the study population) than from low to high (14\%).

Mehta et al. (2019) reported that mindfulness meditation significantly increased Natural Killer Cell activity and levels of physiological cortisol and melatonin, a hormone with anticancer, immunomodulation and hematopoietic properties, (Massion et al., Srinivasan et al., cited in Mehta et al., 2019) in cancer patients. All these effects contribute to slowing the progression of the disease. Other variables, reported by the authors, that showed significant improvement includes: distress, pain intensity, side effect from conventional therapy and other symptom burden (such as fatigue and cachexia), and immune restoration (increase in TNF $\alpha$ and IL-6 levels).

Berk et al. (2018) associated mindfulness meditation with decrease in memory deterioration and increase in cognitive reserve and memory self-efficacy. Several theories have been put forward to explain how mindfulness meditation may prevent age-related dementia. Increase in regional brain perfusion, attenuation of associated risk factors, neuroprotection through increased regional cortical thickness and hypothalamus-pituitary-adrenal axis hyperactivity are some of these hypotheses (Marciniak et al., 2014).

Levine et al. (2017) stated that mindfulness has an ameliorating effect on risk factors for cardiovascular diseases such as atherosclerosis, hypertension, and coronary artery disease. These risk factors include high systolic blood pressure, excessive smoking and tobacco use, insulin resistance, thick carotid intimal, lack of exercise, and high serum lipid levels. The incidence of myocardial ischemia and death from cardiovascular disease were also reported to be lowered.

Cheryl et al. (2017) reported that mindfulness meditation led to a moderate improvement in lung functions in a study population composed of patients with asthma. This can be explained by the fact that mindfulness meditation is a stressreduction intervention and stress leads to histamine release which can trigger broncho-constriction and mucus hypersecretion in asthmatics (Yamauchi and Ogasawara, 2019).

Kabat-Zinn et al. (2017) documented that mindfulness meditation during phototherapy can increase the rate at which the halfway and the end phases of psoriatic lesions clearing is attained by patients with moderate to severe psoriasis.

\section{Positive Effects of Mindfulness Meditation on Some Mental Illnesses}

The link between stress and mental illness is stronger than the link between stress and physical disorders (Salleh, 2008). Thus, the application of mindfulness meditation as therapy for psychiatric disorders is commoner than its therapeutic application to physical illnesses.

For example, Keri Wiginton, a journalist, wrote, in 2018, that nothing, but mindfulness meditation, worked for her depression. Takahashi et al. (2019) reported that mindfulness meditation had moderate to high effects in treating depression. Also, several studies have reported stress-related neuropil volume reductions of some structures in the prefrontal cortex and limbic system, and changes in neuronal plasticity. These modifications are similar to those found, post-mortem, in the grey matters of depressed patients, indicating that MBSR, indeed, has a role in the treatment of depression (Stockmeier and Rajkowska, 2004). Mindfulness has also been shown to be effective in preventing depression relapses (Kuyken et al., 2015; Ma \& Tesdale, 2004; Segal et al., 
2010). The overwhelming reports in favour of the practice's efficacy in preventing depressive relapse has led to: (1) The American Psychiatric Association endorsing it for relapse prevention in individuals with three or more previous depressive episodes (2) the United Kingdom National Institute for Health and Clinical Excellence recommending it over Serotonin Selective Receptor Inhibitors drugs and other conventional therapies for the management of depressive relapse (Crane and Kuyken, cited in Van Dam et al., 2017).

Likewise, Takahashi et al. (2019) reported that mindfulness meditation had moderate to high effect in treating anxiety. Earlier investigations by Hoge et al. (2013)https://www.ncbi.nlm.nih.gov/pmc/articles/PMC37729 79/ - R11 found a mindfulness-associated decrease in anxiety symptoms in patients with Generalized Anxiety Disorder (GAD), and Vollestad et al. (2011) corroborated the report with additional emphasis on the place of mindfulness meditation in Panic Disorder and Social Anxiety Disorder therapy

In 24 meta-analysed studies, mindfulness meditation reduced the consumption of alcohol, cigarettes, amphetamines, marijuana, cocaine, and opiates (Chiesa and Serretti, 2013). This may be due to the fact that mindfulness teaches acceptance of life events which may, otherwise, drive individuals into substance abuse.

Black et al. (2015) reported mindfulness-induced improvement in sleep quality. Ong and Sholtes (2010) reported a case of a patient who after mindfulness therapy, benefited from a 200-minute reduction in awake time span at night, fewer nocturnal awakenings, a nearly doubled total sleep time, an approximately $50 \%$ decrease in pre-sleep arousal, higher sleep quality, and fewer maladaptive beliefs and attitudes about sleep. Furthermore, Colgan et al. (2017) reported reduction in day-time fatigue in participants of a randomized clinical trial.

Colgan et al. (2017) reported mindfulness-associated improvement in Post-Traumatic Stress Disorder (PTSD) symptoms in military veterans when measured by a standard clinician-administered PTSD scale, and an even more statistically significant improvement when measured by a standard self-reported PTSD checklist. Lori et al. (2018) demonstrated similar results in military veterans.

Luoma and Villatte (2012) stated that a small but evolving body of theory, empirical data and evidence on suicidal behaviour and mindfulness-associated impact on the disorder, align to suggest that mindfulness meditation is negatively correlated with the illness. They, also, put forward the hypothesis that mindfulness significantly contributes to the therapy of suicidality by: improving problem-solving capacity through reduction of overgeneral memory, promoting cognitive defusion over thought suppression, and promoting self-awareness over self-critical brooding. Furthermore, indirect support for the utilization of mindfulness with suicidal individuals comes from evidence demonstrating that acceptance of psychological events reduces experiential avoidance and this change can, in turn, alter problems, like substance abuse, chronic pain, anxiety, depression, and psychosis, that are predictive of suicidality (Hayes et al., 2006).

Menstrually-related mood disorders whose symptoms can be improved by mindfulness meditation includes premenstrual syndrome (Panahi and Faramarzi, 2016) and its severe form, pre-menstrual dysphoric disorder (Bluth et al., 2015). Also, mindfulness has been shown to improve menopauseassociated mood swings (Wong et al., 2018).

\section{Benefits of Mindfulness Meditation to Healthcare Workers and Students and Informal Caregivers}

It is a well-known argument that healthcare practitioners are one of the most overworked and underpaid professionals globally. This is due to the constantly soaring patient-tohealth worker ratio. Hence, it is not surprising that several studies have also established the increased risk for chronic stress and mental illnesses among them and healthcare students with emphasis being laid on their heavy course load and their unprepared transition into the morbidity and mortality scene as contributory factors. Informal care givers, taking care of their sick, young and/or elderly relatives, are, also, not spared from this reality. Fortunately, scientific evidence is building up to indicate that mindfulness meditation plays a role in preventing emotional exhaustion, job dissatisfaction, burnout and attrition of these individuals, and in increasing their empathic interactions with patients and care recipients (Fortney et al., 2013). These benefits can be touted as a result of the effects of mindfulness meditation previously outlined in this article.

\section{Negative Effects of Mindfulness Meditation}

There has been very limited documentation of observed or possible negative effects, whether intrinsic or extrinsic, associated with mindfulness meditation. This has led to a preponderate but indefensible appraisal of the therapy as one with "minimal, if any," adverse effects (Turner et al., 2011) and an unjustified advocacy to "meditate not medicate" (Annels et al., 2016). In fact, the severity of some of the reported negative effects, outlined below, can sometimes be very profound.

Kutz et al. (1985) reported crying, fear and distress (from remembering suppressed bad memories from the past) as effects of the therapy. Craven (1989) reported effects such as nausea, unpleasant proprioception, grandiosity, elation, homicidal and suicidal ideation, sense of guilt, delirium, hallucination, disorganized speech and destructive behavior. Shapiro (1992) reported effects such as pain, depression, panic and anxiety elicited by relaxation, confusion and disorientation, boredom, derealization, decrease/loss of motivation, increased negativity and an ironical dependence on mindfulness meditation. Hasenkamp et al. (2012) described increase activity in the inferior parietal cortex of the brain as a common effect of the practice. This effect might lead to depersonalization and altered perception of time and space (Berkovich-Ohana et al., 2013). Furthermore, hyperconnectivity of the prefontral cortex and limbic system is a reported outcome which can lead to dissociative states (Krause-Utz et al., 2017). Other negative effects of the practice include aggravation of joint and neuromuscular diseases, loss/decrease in appetite (Lusky et al., 2009), PTSD (Banks et al., 2015), increased risk for complex partial epileptic seizures (Jaseja, 2006). Out of these effects, relaxation-induced anxiety and panic may be the most reported one (Van Dam et al., 2017). Also, perhaps what is most striking about these effects is that some of them are direct opposite of the positive effects of the 
practice. Another interesting thing to note is that in Buddhism, negative effects associated with mindfulness meditation are often considered to be normal and essential to the spiritual development journey (Buddhaghosa, cited in Cebolla et al., 2017).

Furthermore, the incidence rate of these negative effects is perhaps on the high side. Shapiro (1992) reported a $62.9 \%$ rate, highlighting that the length of the therapy did not affect the severity and frequency of these effects. Also, the result of a multicenter survey showed a $25.4 \%$ rate, especially in individuals practising mindfulness meditation alone and for longer than 20 minutes (Cebolla et al., 2017).

\section{Popular Criticisms of Mindfulness Meditation}

There are concerns that the widespread use of the practice is immature considering that there are several criticisms levelled against it (Greenberg and Harris, 2012). The most popular of these criticisms pivot around the methodological issues arising during research into the practice. These issues include, but are not limited to: (1) Small/modest study population size (2) Limited variation of the bio-data and other personal information profile of the total study population or participants in allocated groups (3) Sample attrition from high participant drop-rate and/or limited/incomplete follow-up on participants due to actions of the investigators and/or participants (4) Lack of randomization and/or appropriate control group (5) Majority of studies not moving beyond Stage 2A (of the National Institute of Health Stage Model of Clinical Science) due to lack of or inadequate active comparison groups (6) Prevalence of patient-unblinded study design (7) Inadequate or lack of access by independent researchers to patient-level data in hospitals or clinics (8) Inadequate knowledge and/or experience of researchers in the practice (9) Poor translation of the knowledge and experience of trainers into knowledge/skill acquisition by learners (10) Lack of scrupulously derived psychological theories to guide the formulation and design of empirical studies (11) Relatively short study duration (12) Inadequate meta-analyses and systematic reviews of available research data (13) Inadequate studies conducted outside the research context.

Another popular criticism is the fact that just like with many newly discovered therapies, there is a probability of publication bias skewed towards reports of positive effects of mindfulness meditation. Sometimes, this bias can be unintended, resulting when investigators are enthusiastic meditators themselves and have strong belief in the benefits of the practice. Other times, the bias can be intended when researchers falsify or replicate data. Unfortunately, these irregularities are not easily detected due to inadequate independent verification of reported research findings. Moreover, even when such verifications are conducted, the haphazard variability of the study designs makes their outcomes flawed. Critics claim that this variability is due to the lack of consensus on the meaning, scope and operationalization of the mindfulness construct (Van Dam et al., 2017).

Furthermore, some reports of findings lack proper delineation of the type of meditation practiced by the study population. For example, in 2017, the US National Health Insurance Survey reported a $200 \%$ and a $800 \%$ respective increase in the rate at which adults and children in the US practised meditation between 2012 and 2017. However, this report failed to specify the type of meditation practised but it has been widely disseminated as proof of the popularity of mindfulness meditation despite the fact that meditation is not the same as mindfulness meditation. This kind of ambiguity in a report gives room for reasonable doubt and this has been an area of huge criticism.

\section{Limitations of Mindfulness Meditation}

Absence/inadequate measure of mindfulness in multicomponent mindfulness-based therapy profoundly limits conclusions about the influence of mindfulness on a disease/illness of interest. Another major limitation of the practice is the lack of methods, techniques or strategies to objectively and accurately assess the capacity of mindfulness trainers. This reality is understandable considering the complexity of the mindfulness construct and its openness for varying interpretations. Another issue of interpretation that greatly limits the practice is language disparity between trainers and learners. During the process of language translation, some key concepts of the practice can be lost, misinterpreted or misunderstood.

Also, it has been reported that the potential of mindfulness meditation is limited by the high probability that the practice will not be beneficial for all due to the multitude of interpersonal differences among populations. Also, certain disease/illness conditions (e.g. psychosis, coma etc.) are contra-indications to the therapy. Moreover, as a psychological, not a physical, construct, there is limitation to the mindfulness outcome parameters that can be assessed objectively. This leads to an inevitable reliance on patients' self-report of outcomes which are vulnerable to limitations of introspection because patients may not know the exact aspect(s) of psychological state that should be taken into consideration in assessing outcomes of the practice. Even when they possess this knowledge, it requires a special kind of multitasking, which most people do not have, to successfully link past events, moods and experiences to accurately assess the nomothetic span of mindfulness outcomes (Van Dam et al., 2017). In addition, there is a tendency for social-desirability bias in patients' self-reports which further impedes the accuracy of such reports.

Also, not every researcher agrees that overdependence on patients' self-reports of outcomes is a problem. Although the logical positivistic philosophical view posits that questionnaire-based scales for assessing outcomes lack accuracy, some researchers hold an alternative nonjustificationist view which opposes this theory (Van Dam et al., 2017). The lack of consensus on the need for an objective psychological construct measurement design, limits the potential for innovation in the assessment of mindfulness outcomes.

\section{Factors in Favour of the Incorporation of Mindfulness Meditation into African Healthcare Systems}

Perhaps the therapy's greatest strength is its ease for adaptation into any healthcare scene due to its low cost of utilization. This factor is especially advantageous for African healthcare systems due to the presence of inequalities in the 
systems. Unlike pharmaceutical products which requires continued purchase throughout the duration of a disease/illness, a clinician's introduction and modification of the practice can be done through few, sometimes one, paid consultation session(s) from which additional healthcare services can also be obtained. Moreover, guides for practising mindfulness meditation can be administered via several free or low-cost channels such as audiotapes, webinars, written online articles etc. Its effective administration through these channels is also a testament to the therapy's capacity to adequately utilize technology for its development.

Another standout advantage of mindfulness meditation is that it is easy to practise, regardless of the educational status, or physical fitness status (a drawback for movement-based therapy) of the learner. This makes the practice suitable for the African clime considering that the continent has the highest rate of education exclusion (UNESCO, n.d.) and a rapidly increasing number of disabled people, estimated to currently be about 80 million people (Kwenda, 2010). Another factor that promotes the practice's incorporation into any healthcare system is the possibility of group therapy considering that: (1) Group therapy can lead to a greater sense of interconnectivity, togetherness and shared humanity which promotes global citizenship (2) Some individuals learn better in groups (3) Group therapy saves the time of the healthcare provider: this is perhaps the most apparent reason why group therapy is a factor that promotes the incorporation of mindfulness meditation into African healthcare systems considering that only approximately $3 \%$ of the world's healthcare workers are in Africa (Mash et al., 2018) despite the continent being the second most populous one.

\section{Factors Not in Favour of the Incorporation of} Mindfulness Meditation into African Healthcare Systems

Although there is a general limitation of research studying the practice among different populations, data from the African population is relatively smaller. This lack of data might undermine the usefulness potential of the practice in the eyes of African policy makers and rightfully so. Also, there is a substantial lack of trained meditators in Africa who have any form of professional experience in clinically modifying the practice. This translates to the need for recruitment of mindfulness meditation trainers from abroad, a venture that is not cheap. Moreover, it will take a special level of multitasking for Africa-based alternative healthcare practitioners and nonspecialist conventional healthcare practitioners to juggle between executing their professional duties and acquiring adequate knowledge of the practice from the abroad-based trainers. Some of these workers might protest against making this knowledge acquisition compulsory for them and they would be within their rights. Even if the government decides to make knowledge of the therapy only compulsory for healthcare students, there will be a resultant increase in the already heavy bulk of academic requirement for them to become professionally certified. This increase might not be the best decision considering the burden the academic workload of these students has placed on some of their mental health (as previously highlighted in this article). Also, even if the knowledge acquisition is recommended but left as a matter of choice for the students, they might not always make the right decision due to their competitive nature and desire for selfactualization. Furthermore, even when the chain of knowledge transfer between abroad and home-based healthcare workers is complete, administering this therapy will increase the workload of home-based healthcare workers by increasing their interaction time with patients, especially when group therapy is not possible.

Furthermore, like with every novel therapy, there is a high possibility of uncertified healthcare providers hijacking, overhyping and misusing the practice. For example, mindfulness meditation is, sometimes, misleadingly heralded as comparable to antidepressants (Goyal et al., 2014). This problem can be compounded by the low level of education in the continent i.e. most patients in Africa will likely not be able to question the hype being presented to them. Also, this low level of education will predispose some patients to misunderstanding the degree of effectiveness of mindfulness meditation and thus, making it their mainstay therapy which can, sometimes, lead to complications of their ailment. Furthermore, there is a non-negligible risk of a sense of letdown and disappointment among patients receiving the therapy considering that reports show that the therapy may not work maximally, are ineffective or contra-indicated in some individuals (Dobkin, Irving, and Amar, 2012).

Another factor that might not favour the incorporation of the practice into African healthcare systems is the tendency for policymakers to consider the incorporation as a shift of the focus of attention from more urgent matters of healthcare revitalization seeking redress e.g. Universal Healthcare Coverage.

\section{Recommendations}

Before mindfulness meditation is incorporated into African healthcare systems, further research should be carried out on the subject matter. These studies should be adequately powered to meet their primary outcomes. Researchers should practice methodological rigor and also take into serious consideration other criticisms of the practice in developing innovative study designs and in reporting findings. In addition, such studies, to the extent possible, should: (1) Be multi-modal i.e. they should utilize mixed methods to assess the direct and indirect biological, physical, cognitive, emotional, mental, behavioural and social impacts (both positive and negative) of the practice. (2) Be thorough. For example, a study on the negative effects of the practice should not only assess what these effects are but also if they are intrinsic to the practice, transitory, require medical support and/or discontinuation of the practice for relief (3) Be conducted by a team of adversarial and multi-disciplinary colleagues. This team should also include researchers sceptical about the hype enjoyed by the practice. (4) Operationalize alternative conceptualizations of the mindfulness construct (5) Utilise both theory-driven and data-driven approaches to generating result (6) Establish alternative but reliable methods for measuring mindfulness (7) Provide clarity regarding mindfulness change as an active component of study outcomes. Van Dam et al. (2017) offers further insight on how future studies should be configured.

Furthermore, if the practice is to be incorporated into African healthcare systems, standardized and regulated 
service provision guidelines, informed by proper research, should be adopted, disseminated and continually reviewed. Also, the government should facilitate collaboration between conventional and traditional healthcare providers in order to promote efficacy in the administration of the service. In addition, the government should develop the traditional healthcare sector, and providers should be encouraged to get certified and accredited in the practice with adequate remuneration for their service provision as an incentive. Also, assurance should be provided to traditional healthcare providers that the new practice is meant to support not to subjugate their previous practices. Furthermore, the general public should be sensitized against the mentality of traditional medicine being too crude, non-modern and non-conforming to the Western standards Africa is fast-adopting. Also, since religion is a sensitive topic in Africa, the public should be made aware of the fact that although mindfulness meditation has its roots in some religions, utilizing the practice for healthcare is not a form of participation in these religions.

Furthermore, the practice should be customized to suit the particular need and personality type of patients. Also, counselling session before and after administration of the therapy should be encouraged. The fears, ideas, feelings and expectations of the patient should be discussed during precounselling sessions. Appreciation and/or distaste of outcomes should be discussed (and taken into consideration during further customization of the practice) and confusion(s) arising from outcomes should be addressed during postcounselling sessions.

\section{CONCLUSION}

Mindfulness, just like the intelligence construct, might inspire several years of learning, relearning and unlearning but still, never be fully understood. However, the currently available body of empirical evidence suggests that the practice should not be left as a fringe area of scientific and public curiosity in Africa, especially in the health sector. In spite of this recommendation, extreme caution should be exercised by policymakers in deciding if mindfulness meditation is a potentially useful tool for improving healthcare in Africa or if it is just a romanticized practice. This caution is required because the reported benefits of the practice do not overwhelming outweigh its disadvantages and drawbacks. Also worthy of note is that the practice, as it currently stands, should only be utilized as just an additional link in the chain of therapy.

\section{REFERENCES}

Abdullahi A. A. (2011). Trends and challenges of traditional medicine in Africa. African journal of traditional, complementary, and alternative medicines: AJTCAM, 8(5 Suppl), 115-123. https://doi.org/10.4314/ajtcam.v8i5S.5

Annels, S., Kho, K. and Bridge, P. (2016). Meditate don't medicate: How medical imaging evidence supports the role of meditation in the treatment of depression. Radiography, 22, e54-e58. https://doi.org/10.1016/j.radi.2015.08.002
Baltar, Y. C. and Filgueiras, A. (2018). The Effects of Mindfulness Meditation on Attentional Control During Off-Season Among Football Players. SAGE Open. https://doi.org/10.1177/2158244018781896

Banks, K., Newman E. and Saleem J. (2015). An Overview of the Research on Mindfulness-Based Interventions for Treating Symptoms of Posttraumatic Stress Disorder: A Systematic Review. J Clin Psychol. 71, 935-963. https://doi.org/10.1002/jclp.22200

Berk, L., Warmenhoven, F., van Os, J. and van Boxtel, M. (2018). Mindfulness Training for People With Dementia and Their Caregivers: Rationale, Current Research, and Future Directions. Frontiers in psychology, 9, 982. https://doi.org/10.3389/fpsyg.2018.00982

Berkovich-Ohana, A., Dor-Ziderman, Y., Glicksohn, J. and Goldstein, A. (2013). Alterations in the sense of time, space, and body in the mindfulness-trained brain: a neurophenomenologically-guided MEG study. Frontiers in psychology, 4, 912. https://doi.org/10.3389/fpsyg.2013. 00912

Black, D. S., O’Reilly, G. A., Olmstead, R., Breen, E. C. and Irwin, M. R. (2015). Mindfulness meditation and improvement in sleep quality and daytime impairment among older adults with sleep disturbances: a randomized clinical trial. JAMA internal medicine, 175(4), 494-501. https://doi.org/10.1001/ jamainternmed.2014.8081

Bluth, K., Gaylord, S., Nguyen, K., Bunevicius, A. and Girdler, S. (2015). Mindfulness-based Stress Reduction as a Promising Intervention for Amelioration of Premenstrual Dysphoric Disorder Symptoms. Mindfulness, 6(6), 12921302. https://doi.org/10.1007/s12671-015-0397-4

Brown, K. W., Goodman, R. J., Ryan, R. M. and Anālayo, B. (2016). Mindfulness Enhances Episodic Memory Performance: Evidence from a Multimethod Investigation. PloS one, 11(4), e0153309. https://doi.org/10.1371/journal. pone.0153309

Carrière K., Khoury B., Gunak M. M. and Knauper B. (2018). Mindfulness-based interventions for weight loss: a systematic review and meta-analysis. Obesity Reviews, 19(2), 164-177. https://doi.org/10.1111/obr.12623

Cebolla, A., Demarzo, M., Martins, P., Soler, J. and GarciaCampayo, J. (2017). Unwanted effects: Is there a negative side of meditation? A multicentre survey. PloS one, 12(9), e0183137. https://doi.org/10.1371/journal.pone.0183137

Cheryl, M., Karen, L. O. C , Nilani, L. S., Melissa, A. B., Gabriel, B. A. and Marisa, D. C. (2017). Mindful Meditation for Individuals with Asthma and Anxiety: Promising Results from a Multiple Baseline Study. J Yoga Phys Ther, 7, 1. https://doi.org/10.4172/2157-7595.1000262

Chiesa, A. and Serretti A. (2013). Are mindfulness-based interventions effective for substance use disorders? A systematic review of the evidence. Substance Use \& Misuse, 49(5), 492-512. https://doi.org/10.3109/10826084.2013. 770027 
Colgan, D. D., Wahbeh, H., Pleet, M., Besler, K. and Christopher, M. (2017). A Qualitative Study of Mindfulness Among Veterans With Posttraumatic Stress Disorder: Practices Differentially Affect Symptoms, Aspects of WellBeing, and Potential Mechanisms of Action. Journal of evidence-based complementary \& alternative medicine, 22(3), 482-493. https://doi.org/10.1177/2156587216684 999

Craven, J. L. (1989). Meditation and psychotherapy, Canadian Journal of Psychiatry, 34(7), 648-653. https://doi.org/10.1177/070674378903400705

Crescentini, C. and Capurso, V. (2015). Mindfulness meditation and explicit and implicit indicators of personality and self-concept changes. Frontiers in psychology, 6, 44. https://doi.org/10.3389/fpsyg.2015. 00044

Crescentini, C., Matiz, A., Cimenti, M., Pascoli, E., Eleopra, R. and Fabbro, F. (2018). Effect of Mindfulness Meditation on Personality and Psychological Well-being in Patients with Multiple Sclerosis. International journal of MS care, 20(3), 101-108. https://doi.org/10.7224/1537-2073.2016-093

Creswell J. D. (2016). Mindfulness Interventions. Annual Review of Psychology, 68, 491-516. https://doi.org/10.1146/ annurev-psych-042716-051139

Creswell, J. D., Myers, H. F., Cole, S. W. and Irwin, M. R. (2009). Mindfulness meditation training effects on $\mathrm{CD} 4+\mathrm{T}$ lymphocytes in HIV-1 infected adults: a small randomized controlled trial. Brain, behavior, and immunity, 23(2), 184188. https://doi.org/10.1016/j.bbi.2008.07.004

Ding, X., Tang, Y. Y., Tang, R. and Posner, M. I. (2014). Improving creativity performance by short-term meditation. Behavioral and brain functions: BBF, 10, 9. https://doi.org/10.1186/1744-9081-10-9

Dobkin, P. L., Irving, J. A. and Amar, S. (2012). For whom may participation in a mindfulness-based stress reduction program be contraindicated? Mindfulness, 3(1), 44-50. https://doi.org/10.1007/s12671-011-0079-9

Filgueiras, A., de Oliveira Galvão, B., Pires, P., FioravantiBastos, A. C. M., Hora, G. P. R., Santana, C. M. T. and Landeira-Fernandez, J. (2015). Translation and semantic adaptation of the Attentional Control Scale for the Brazilian context. Estudos de Psicologia (Campinas), 32, 173-185.https://doi.org/10.1590/0103166X2015000200003

Fortney, L., Luchterhand, C., Zakletskaia, L., Zgierska, A. and Rakel, D. (2013). Abbreviated mindfulness intervention for job satisfaction, quality of life, and compassion in primary care clinicians: a pilot study. Annals of family medicine, 11(5), 412-420. https://doi.org/10.1370/afm.151

Gallant S. N. (2016). Mindfulness meditation practice and executive functioning: Breaking down the benefit. Consciousness and Cognition, 40, 116-30. https://doi.org/10.1016/j.concog.2016.01.005

Goyal, M., Singh, S., Sibinga, E. M., Gould, N. F., RowlandSeymour, A., Sharma, R., ... Haythornthwaite, J. A. (2014). Meditation programs for psychological stress and wellbeing: a systematic review and meta-analysis. JAMA internal medicine, 174(3), 357-368. https://doi.org/10.1001/ jamainternmed.2013.13018
Goyal, M., Singh, S., Sibinga, E. M., Gould, N. F., RowlandSeymour, A., Sharma, R., ... Haythornthwaite, J. A. (2014). Meditation programs for psychological stress and wellbeing: a systematic review and meta-analysis. JAMA internal medicine, 174(3), 357-368. https://doi.org/10.1001/ jamainternmed.2013.13018

Greenberg, M. T. and Harris A. R. (2012). Nurturing mindfulness in children and youth: Current state of research. Child Development Perspectives 6 (2), 161-166. https://doi.org/10.1111/j.1750-8606.2011.00215.x

Hasenkamp, W. and Barsalou, L. W. (2012). Effects of meditation experience on functional connectivity of distributed brain networks. Frontiers in human neuroscience, 6, 38. https://doi.org/10.3389/fnhum.2012. 00038

Hayes, S. C, Luoma, J. B., Bond, F. W., Masuda, A. and Lillis J. (2006). Acceptance and commitment therapy: model, processes and outcomes. Behaivour research and therapy, 44(1), 1-25. https://doi.org/10.1016/j.brat.2005.06.006

Hjelm, L., Handa, S., de Hoop, J., Palermo, T., Zambia CGP and MCP Evaluation Team. (2017). Poverty and perceived stress: Evidence from two unconditional cash transfer programs in Zambia. Social Science and Medicine, 177, 110117. https://doi.org/10.1016/j.socscimed.2017.01.023

Hoge, E. A., Bui, E., Marques, L., Metcalf, C. A., Morris, L. K., Robinaugh, D. J., ... Simon, N. M. (2013). Randomized controlled trial of mindfulness meditation for generalized anxiety disorder: effects on anxiety and stress reactivity. The Journal of clinical psychiatry, 74(8), 786-792. https://doi.org/10.4088/JCP.12m08083

Hölzel B. K., Ott U., Hempel H., Hackl A., Wolf K., Stark R. and Vaitl D. (2007). Differential engagement of anterior cingulate and adjacent medial frontal cortex in adept meditators and non-meditators. Neuroscience Letters, 421, 16-21. https://doi.org/10.1016/j.neulet.2007.04.074

Hölzel, B. K., Carmody, J., Vangel, M., Congleton, C., Yerramsetti, S. M., Gard, T. and Lazar, S. W. (2011). Mindfulness practice leads to increases in regional brain gray matter density. Psychiatry research, 191(1), 36-43. https://doi.org/10.1016/j.pscychresns.2010.08.006

Jaseja, H. (2006). Meditation potentially capable of increasing susceptibility to epilepsy-a follow-up hypothesis. Med Hypotheses, 66, 925-928. https://doi.org/10.1016/j.mehy. 2005.11.043

Kabat-Zinn, J., Wheeler, E., Light, T., Skillings, A., Scharf, M. J., Cropley, T. G., ... Bernhard, J. D. (1998). Influence of a mindfulness meditation-based stress reduction intervention on rates of skin clearing in patients with moderate to severe psoriasis undergoing phototherapy (UVB) and photochemotherapy (PUVA). Psychosomatic Medicine, 60(5), 625-32. https://doi.org/10.1097/00006842199809000-00020

KayLoni, O. L., Emery, C. F. (2015). Mindfulness and Weight Loss: a systematic review. Psychosomatic Medicine, 77(1), 59-67. https://doi.org/10.1097/PSY.0000000000000127 
Krause-Utz, A., Frost, R., Winter, D. and Elzinga, B. M. (2017). Dissociation and Alterations in Brain Function and Structure: Implications for Borderline Personality Disorder. Current psychiatry reports, 19(1), 6. https://doi.org/10.1007/s11920-017-0757-y

Kutz, I., Leserman, J., Dorrington, C., Morrison, C.H., Borysenko, J. and Benson, H. (1985). Meditation as an adjunct to psychotherapy, an outcome study. Psychotherapy Psychosomatics, 43, 209-218. https://doi.org/10.1159/000287881

Kwenda, S. (2010). Africa's disabled will not be forgotten. Available at: https://www.un.org/africarenewal/magazine/ april-2010/africa\%E2\%80\%99s-disabled-will-not-beforgotten (Accessed 6 April 2020).

Levine, G. N., Lange, R. A., Bairey-Merz, C. N., Davidson, R. J., Jamerson, K., Mehta, P. K., ... American Heart Association Council on Clinical Cardiology; Council on Cardiovascular and Stroke Nursing; and Council on Hypertension. (2017). Meditation and Cardiovascular Risk Reduction: A Scientific Statement From the American Heart Association. Journal of the American Heart Association, 6(10), e002218. https://doi.org/10.1161/JAHA.117.002218

Lori, L. D., Whetsell, C., Hamner, M. B., Carmody, J., Rothbaum, B. O., Allen, R. S., ... Bremner J. D. (2018). A Multisite Randomized Controlled Trial of MindfulnessBased Stress Reduction in the Treatment of Posttraumatic Stress Disorder. Psych Res Clin Pract 1, 2. https://doi.org/10.1176/appi.prcp.20180002

Luoma, J. B. and Villatte, J. L. (2012). Mindfulness in the Treatment of Suicidal Individuals. Cognitive and behavioral practice, 19(2), 265-276. https://doi.org/10.1016/j.cbpra. 2010.12.003

Lustyk, M. K. B., Chawla, N., Nolan, R. S. and Marlatt, G. A. (n.d.) Mindfulness meditation research: issues of participant screening, safety procedures, and researcher training. Adv Mind Body Med, 24, 20-30.

Ma, S. H. and Teasdale, J. D. (2004). Mindfulness-based cognitive therapy for depression: Replication and exploration of differential relapse prevention effects. Journal of Consulting and Clinical Psychology, 72, 31-40. https://doi.org/10.1037/0022-006X.72.1.31

Marciniak, R., Sheardova, K., Cermáková, P., Hudeček, D., Sumec, R. and Hort, J. (2014). Effect of meditation on cognitive functions in context of aging and neurodegenerative diseases. Frontiers in behavioral neuroscience, 8, 17. https://doi.org/10.3389/fnbeh.2014. 00017

Mash, R., Howe, A., Olayemi, O., Makwero, M., Ray, S., Zerihun, M., Gyuse, A. and Goodyear-Smith, F. (2018). Reflections on family medicine and primary healthcare in sub-Saharan Africa. BMJ global health, 3(Suppl 3), e000662. https://doi.org/10.1136/bmigh-2017-000662

Mehta, R., Sharma, K., Potters, L., Wernicke, A. G. and Parashar, B. (2019). Evidence for the Role of Mindfulness in Cancer: Benefits and Techniques. Cureus, 11(5), e4629. https://doi.org/10.7759/cureus.4629
Meier M. E. and Kane M. J. (2015) Carving executive control at its joints: Working memory capacity predicts stimulusstimulus, but not stimulus-response, conflict. Journal of Experimental psychology: Learning, Memory, and Cognition, 41(6), 1849-1872. https://doi.org/10.1037/xlm0000147

Norris, C. J., Creem, D., Hendler, R. and Kober, H. (2018). Brief Mindfulness Meditation Improves Attention in Novices: Evidence From ERPs and Moderation by Neuroticism. Frontiers in human neuroscience, 12, 315. https://doi.org/10.3389/fnhum.2018.00315

Norris, C. J., Creem, D., Hendler, R. and Kober, H. (2018). Brief Mindfulness Meditation Improves Attention in Novices: Evidence From ERPs and Moderation by Neuroticism. Frontiers in human neuroscience, 12, 315. https://doi.org/10.3389/fnhum.2018.00315

Ong, J. and Sholtes, D. (2010). A mindfulness-based approach to the treatment of insomnia. Journal of clinical psychology, 66(11), 1175-1184. https://doi.org/10.1002/jclp.20736

Panahi, F. and Faramarzi, M. (2016). The Effects of Mindfulness-Based Cognitive Therapy on Depression and Anxiety in Women with Premenstrual Syndrome. Depression research and treatment, 2016, 9816481. https://doi.org/10.1155/2016/9816481

Prabhu, V., Sutton, C. and Sauser, W. (2008). Creativity and certain personality traits: Understanding the mediating effect of intrinsic motivation. Creativity Research Journal, 20(1), 53-66. https://doi.org/10.1080/10400410701841955

Robins, J. L., Kiken, L., Holt, M. and McCain, N. L. (2014). Mindfulness: an effective coaching tool for improving physical and mental health. Journal of the American Association of Nurse Practitioners, 26(9), 511-518. https://doi.org/10.1002/2327-6924.12086

Salleh M. R. (2008). Life event, stress and illness. The Malaysian journal of medical sciences: MJMS, 15(4), 9-18. Available at: https:/www.ncbi.nlm.nih.gov/pmc/articles/ PMC3341916/\#

Sedlmeier, P., Eberth, J., Schwarz, M., Zimmermann, D., Haarig, F., Jaeger, S. and Kunze, S. (2012). The psychological effects of meditation: A meta-analysis. Psychological Bulletin, 138(6), 1139-1171. https://doi.org/10.1037/a0028168

Shapiro, D. H. (1992). Adverse effects of meditation: a preliminary investigation of long-term meditators. International Journal of Psychosomatics, 39, 62-67.

Stockmeier, C. A. and Rajkowska, G. (2004). Cellular abnormalities in depression: evidence from postmortem brain tissue. Dialogues in clinical neuroscience, 6(2), 185197.

Takahashi, T., Sugiyama, F., Kikai, T., Kawashima, I., Guan, S., Oguchi, M., Uchida, T. and Kumano, H. (2019). Changes in depression and anxiety through mindfulness group therapy in Japan: the role of mindfulness and self-compassion as possible mediators. BioPsychoSocial medicine, 13, 4. https://doi.org/10.1186/s13030-019-0145-4 
Turner, L., Singh, K., Garrity, C., Tsertsvadze, A., Manheimer, E., Wieland, L., ... Moher, D. (2011). An evaluation of the completeness of safety reporting in reports of complementary and alternative medicine trials. $B M C$ Complementary and Alternative Medicine, 11, 67. https://doi.org/10.1186/1472-6882-11-67

United Nations Educational, Scientific and Cultural Organization (n.d.). Education in Africa. Available at: http://uis.unesco.org/en/topic/education-africa (Accessed 6 April 2020).

Van Dam, N. T., van Vugt, M. K., Vago, D. R., Schmalzl, L., Saron, C. D., Olendzki, A., ... Meyer, D. E. (2017). Mind the Hype: A Critical Evaluation and Prescriptive Agenda for Research on Mindfulness and Meditation. Perspectives on psychological science: a journal of the Association for Psychological Science, 13(1), 36-61. https://doi.org/10.1177/1745691617709589

Victorson, D., Kentor, M., Maletich, C., Lawton, R. C., Kaufman, V. H., Borrero, M., Berkowitz, C. (2015). Mindfulness Meditation to Promote Wellness and Manage Chronic Disease: A Systematic Review and Meta-Analysis of Mindfulness-Based Randomized Controlled Trials Relevant to Lifestyle Medicine. American Journal of Lifestyle Medicine, 9(3), 185-211. https://doi.org/10.1177/15598276 14537789

Vøllestad, J., Sivertsen, B. and Nielsen, G. H. (2011). Mindfulness-based stress reduction for patients with anxiety disorders: evaluation in a randomized controlled trial. Behaivour research and therapy, 49(4), 281-8. https://doi.org/10.1016/j.brat.2011.01.007
Wahbeh, H., Elsas, S. M. and Oken, B. S. (2008). Mind-body interventions: applications in neurology. Neurology, 70(24), 2321-2328. https://doi.org/10.1212/01.wnl.0000314667.16386.5e

Webb, L., Perry-Parrish, C., Ellen, J. M. and Sibinga, E. M. (2017). Mindfulness instruction for HIV-infected youth: a randomized controlled trial. AIDS Care, 26, 1-8. https://doi.org/10.1080/09540121.2017.1394434

Wong, C., Yip, B. H., Gao, T., Lam, K., Woo, D., Yip, A., ... Wong, S. (2018). Mindfulness-Based Stress Reduction (MBSR) or Psychoeducation for the Reduction of Menopausal Symptoms: A Randomized, Controlled Clinical Trial. Scientific reports, 8(1), 6609. https://doi.org/10.1038/s41598-018-24945-4

Wu, R., Liu, L. L., Zhu, H., Su, W. J., Cao, Z. Y., Zhong, S. Y., Liu, X. H. and Jiang, C. L. (2019). Brief Mindfulness Meditation Improves Emotion Processing. Frontiers in neuroscience, 13, 1074. https://doi.org/10.3389/fnins.2019. 01074

Yamauchi, K. and Ogasawara, M. (2019). The Role of Histamine in the Pathophysiology of Asthma and the Clinical Efficacy of Antihistamines in Asthma Therapy. International journal of molecular sciences, 20(7), 1733. https://doi.org/10.3390/ijms20071733

Zeidan, F., Johnson, S. K., Diamond, B. J., David, Z. and Goolkasian, P. (2010). Mindfulness meditation improves cognition: Evidence of brief mental training. Consciousness and Cognition, 19(2), 597-605. https://doi.org/10.1016/ j.concog.2010.03.014

Zenasni, F. and Lubart, T. (2002). Effects of mood states on creativity. Current Psychology Letters: Behaviour, Brain \& Cognition, 8, 33-50. Available at: http://journals.openedition.org/cpl/205 